\title{
The Toronto Obsessive-Compulsive Scale: Psychometrics of a Dimensional Measure of Obsessive-Compulsive Features
}

Laura S. Park, Christie L. Burton, Annie Dupuis, Janet Shan, Eric A. Storch, Jennifer Crosbie, Russell J. Schachar, Paul D. Arnold

Version Post-print/accepted manuscript

Citation Park LS, Burton CL, Dupuis A, Shan J, Storch EA, Crosbie J, Schachar (published version) RJ, Arnold PD. The Toronto Obsessive-Compulsive Scale: psychometrics of a dimensional measure of obsessive-compulsive traits. Journal of the American Academy of Child \& Adolescent Psychiatry. 2016 Apr 30;55(4):310-8.

Additional Publisher The published version of this article can be found at Information https://doi.org/10.1016/j.jaac.2016.01.008.

Copyright/License

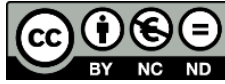

(C) 2016. This work is licensed under the Creative Commons Attribution-NonCommercial-NoDerivatives 4.0 International License. To view a copy of this license, visit http://creativecommons.org/licenses/by-nc-nd/4.0/.

How to cite TSpace items

Always cite the published version, so the author(s) will receive recognition through services that track citation counts, e.g. Scopus. If you need to cite the page number of the author manuscript from TSpace because you cannot access the published version, then cite the TSpace version in addition to the published version using the permanent URI (handle) found on the record page.

This article was made openly accessible by $U$ of $T$ Faculty. Please tell us how this access benefits you. Your story matters. 


\section{The Toronto Obsessive-Compulsive Scale: Psychometrics of a Dimensional Measure of}

\section{Obsessive-Compulsive Features}

Journal of the American Academy of Child and Adolescent Psychiatry (2016), 55(4), 310-318.

Laura S. Park ${ }^{1}$, M.Sc., Christie L. Burton², PhD., Annie Dupuis ${ }^{3,5}$, PhD., Janet Shan ${ }^{1}$, M.Sc., Eric A.

Storch ${ }^{7,8,9}$, PhD., Jennifer Crosbie ${ }^{1,4}$, PhD, Russell J. Schachar ${ }^{1,4}$, MD., Paul D. Arnold $\ddagger^{2,4,6}$, MD, PhD.

${ }^{1}$ Neurosciences and Mental Health, ${ }^{2}$ Genetics and Genome Biology Programs, ${ }^{3}$ Clinical research services; Hospital for Sick Children, Toronto, Canada.

${ }^{4}$ Department of Psychiatry \& ${ }^{5}$ Dalla Lana School of Public Health, University of Toronto; Toronto, Canada. ${ }^{6}$ Mathison Centre for Mental Health Research and Education; University of Calgary, Calgary, Canada.

${ }^{7}$ Department of Pediatrics, Health Policy and Management, Psychiatry \& Neurosciences, and Psychology; University of South Florida, Tampa, Florida.

${ }^{8}$ Rogers Behavioral Health; Tampa, Florida,

${ }^{9}$ All Children's Hospital; John's Hopkins Medicine, St. Petersburg, Florida.

\section{‡Corresponding Author:}

Paul Arnold, MD, PhD

TRW Building, 4th Floor, Room 4D60, 3280 Hospital Drive NW, Calgary Alberta, T2N 4N1, Canada. Email:

Email: paul.arnold@ucalgary.ca

Keywords: obsessive-compulsive disorder, psychometrics, the Toronto Obsessive-Compulsive Scale (TOCS), general pediatric population, obsessive-compulsive features

Published article can be found at: http://dx.doi.org/10.1016/i.jaac.2016.01.008 


\section{ABSTRACT}

\section{Objective:}

To describe the Toronto Obsessive-Compulsive Scale (TOCS), a novel 21-item parent- or self-report questionnaire, that covers wide variation in obsessive-compulsive (OC) traits, and to evaluate its psychometric properties in a community-based pediatric sample.

\section{Method:}

The TOCS was completed for 16,718 children and adolescents between the ages of 6 and 17 years in a community setting. Internal consistency, convergent validity with the Obsessive Compulsive Scale of the Child Behavior Checklist (CBCL-OCS), divergent validity with the Strengths and Weaknesses of ADHD Symptoms and Normal Behaviour Rating Scale (SWAN), inter-rater reliability, and sensitivity and specificity of the TOCS were assessed.

\section{Results:}

The internal consistency of the 21 TOCS items was excellent (Cronbach's $\alpha=0.94$ ). TOCS was moderately correlated with the Obsessive-Compulsive Scale of the Child Behavior Checklist (Spearman correlation=0.51) and poorly correlated with the SWAN (Pearson Correlation=0.02). Sensitivity and specificity analyses indicated that TOCS total score of greater than 0 successfully discriminated community-reported obsessive-compulsive disorder (OCD) cases from non-cases. OC traits were continuously distributed both at the total score and dimensional level in our pediatric community sample.

\section{Conclusions:}

TOCS is a multidimensional measure of OC traits in children and adolescents with sound psychometric properties. TOCS reveals that OC traits are common and continuously distributed in a community sample. TOCS may be a useful measure for studies of the characteristics and etiology of OC traits. 
There is a growing trend toward to view mental illnesses as extremes of traits that are continuously distributed in the general population ${ }^{1-3}$. The trend is true also for OCD although there is a lack of evidence about the distribution of $\mathrm{OC}$ traits in the general population. Epidemiological studies have examined OCD using a categorical approach, grouping population samples into clinical, sub-clinical, and healthy control groups ${ }^{4-7}$. These studies find that $2-19 \%$ of individuals have subclinical OCD ${ }^{5-9}$ meaning that they meet some, but not all, DSM criteria for the disorder $5,6,9-14$. The prevalence of sub-clinical OCD suggests that OCD may be the extreme of widely distributed OC traits many of which can be present in the absence of an OCD diagnosis. Individuals with subclinical OCD not only experience impairment in relationships and quality of life ${ }^{13}$, but also exhibit some characteristics that do not differ from those who meet all DSM criteria for OCD.5,6,15

One impediment to a better understanding of $O C$ traits in the general population is the structure of existing OCD rating scales. For example, the Leyton Obsessional Inventory (LOI) requires rating of $O C$ features on a $0-2$ scale where 0 indicates the absence of a clinically significant symptom and 2 indicates the presence of a severe symptom. Although useful in clinical settings, scales such as the LOI are insensitive to more minor variation amongst people who have no clinically significant symptoms but may have some, or possibly many, OC traits. What is needed is a dimensional measure of $\mathrm{OC}$ traits with broader rating options that can capture variation in OC traits in the presence or absence of clinically significant symptoms.

We developed the Toronto Obsessive-Compulsive Scale (TOCS) to address the need for a quantitative and multidimensional measure of OC traits among children and adolescents which could be used to examine the full distribution of OC traits in a general population of youth. We report the psychometric properties of the TOCS in a large, community sample of children and adolescence (16, 718 children and adolescents between the ages of 6 and 17 years). More specifically, we evaluated internal consistency, convergent and divergent validity, parent-child agreement, as well as sensitivity and specificity of the TOCS. 


\section{Participants}

\section{METHOD}

17,263 children and adolescents between the ages of 6 and 17 years were recruited to the Thoughts, Actions and Genes (TAG) project at the Ontario Science Centre (OSC) in Toronto, Canada. The OSC is a popular science museum and tourist attraction with interactive science and technology exhibits and programs, especially well attended by children and adolescents. Visitors to the OSC were invited to participate in the TAG project if interested. Informed consent and/or verbal assent approved by the Hospital for Sick Children Research Ethics Board were obtained from all participants.

Phenotypic information was collected using a computerized questionnaire, completed mostly by parents of the participants or the participant themselves. After screening for missing and invalid questionnaire information, our final sample size for the current study was 16,718 participants (mean age 11.1 years; SD +/- 2.8 years). The sample consisted of 8447 (50.5\%) males and 8271 (49.5\%) females from various ethnic backgrounds reflective of the Toronto population. Detailed demographic information is outlined in Table 1. Although most of the questionnaire information was parent-reported, we were able to obtain both self-reported and parent-reported information on OC traits from a subset of our sample ( $n=332$ parent-child pairs).

\section{Measures}

OC Traits. OC traits were measured using the TOCS and the CBCL-OCS. The TOCS is a scale developed by our group to measure common OC traits seen in both clinic and general population settings. The TOCS consists of 21 items that were developed from two previously published scales (e.g., child version of the Obsessive Compulsive Inventory [OCI-CV] ${ }^{16}$ and the child version of the LOI $[\mathrm{LOI}-\mathrm{CV}]^{17,18}$ ). We reviewed the scales and selected items that cover the major symptom dimensions previously identified in $\mathrm{OCD}^{19}$. Items were re-worded to be suitable for not only clinical, 
but also community-based samples. For example, in the LOI-CV the item "I was fussy about keeping my hands clean" is very similar to the OCI-CV item "I wash my hands more than other kids". On the TOCS, the corresponding item is, "Needs to wash his/her hands". Based on these considerations, the scale items were first drafted by a group of the authors (PA, RS, JC), circulated to other OCD experts for comments (including ES) and then modified based on this feedback. Although the content of the TOCS was based on previous OCD scales, we modified the scoring of the items to capture the widest possible distribution of responses. Each of the 21 items is scored on a 7-point Likert-type scale: $3=$ far less often than average, $-2=$ less often than average, $-1=$ slightly less often than average, $0=$ average amount of time, $1=$ slightly more often than average, $2=$ more often than average and $3=$ far more often than average. In the example just given, a parent could rate "Needs to wash his/her hands" on a broad range ranging from 'far less often' to 'far more often' than average, whereas on the OCI-CV or LOI-CV there is no option to rate the behaviour as occurring less often than average. A factor analysis of the TOCS conducted in this pediatric community sample by our group was consistent with previous factor analysis studies in OCD patients, yielding six OC dimensions: Cleaning/Contamination, Rumination, Symmetry/Ordering, Hoarding, Superstition, and Counting/Checking (Park et al., under review). Dimensions and relevant items are summarized in Table 2. Respondents were asked to make ratings based on the child's traits over the past six months. A total score was calculated by adding each score of the 21 items, and the six dimension scores were calculated by averaging the sum of item scores within each dimension identified from our factor analysis. We considered the participant to endorse an OC trait if they scored either 2 or 3 on a TOCS item. The CBCL-OCS ${ }^{20}$, which consists of 8 items each scored on a 3-point scale, was also completed. Two CBCL-OCS scores were calculated: (1) CBCL-OCS total score, calculated by adding each score of the eight items, and (2) CBCL-OCS weighted score, by weighting each of the eight items according to their predictive value of clinical OCD20. 
ADHD Traits. The Strengths and Weaknesses of ADHD Symptoms and Normal Behaviour Rating Scale (SWAN) was used to collect ADHD-trait information. The SWAN consists of 18 items (9 inattention items and 9 hyperactivity-impulsivity items) measuring both strengths and weaknesses on a 7 -point Likert-type scale $(-3=$ far below average to $+3=$ far above average). Usually, higher SWAN scores indicate strengths in that particular trait reflective of low ADHD traits while lower SWAN scores indicate the presence of ADHD traits. For this paper, the SWAN scores were reversed for easier comparison to the TOCS scores. Therefore, higher SWAN scores indicated higher ADHD traits while lower SWAN scores indicated lower ADHD traits in this study.

General Information. The electronic questionnaire also consisted of questions regarding demographics, family psychiatric history, as well as the child's medical history, psychiatric history and medication information. We also obtained information on whether the participant ever received a diagnosis or received treatment for a psychiatric disorder and used this information as a community-reported diagnosis of the disorder in our analyses.

Statistical Analyses

Psychometric properties, specifically the internal consistency, divergent, convergent, and discriminant validity of the TOCS were assessed using IBM SPSS Statistics 21.0 and SAS 9.4. Cronbach's alpha was used to evaluate the internal consistency of the 21 items of the TOCS as well as each of the six dimensions previously identified in the TOCS (Park et al., under review). Divergent and convergent validity of the TOCS were assessed by performing Pearson's and Spearman's correlations with the SWAN and the CBCL-OCS, respectively. Discriminant validity was examined by comparing the TOCS total and dimension scores between individuals with communityreported ADHD, OCD, ASD, Tic disorder, and any anxiety disorder. In addition, we examined agreement between parent-reported and self-reported OC traits in a subset of participants, using intraclass correlations (ICC) and Wilcoxon signed-rank test. 
To understand the distribution of OC traits in our sample, distribution graphs were plotted and the skewness and kurtosis statistics were obtained for the total CBCL-OCS and TOCS scores, as well as for each of the OC dimension scores. We also examined the frequency of reported OCD and OC traits, as well as any relationships between OC traits and age, or sex. For all analyses, 95\% confidence intervals (CI) were used, and because of our large sample size, we used a stringent pvalue $\leq 0.01$ for the results to be considered as statistically significant.

Receiver operating curves (ROC) were used to estimate optimal sensitivity and specificity of the TOCS total score in our community sample. ROC analyses were conducted to establish optimal thresholds for identifying OCD cases using community-reported diagnoses as a criterion. We calculated specificity and sensitivity for the whole sample and for parent and self-respondents separately as well.

\section{RESULTS}

Psychometric Properties of the TOCS

Internal Consistency. Cronbach's alpha indicated strong internal consistency for the 21 items on the TOCS (0.94). Even after removing the two items ("homework" and "upsetting") that were excluded from the factor analysis as discussed in Park et al. (under review), the Cronbach's alpha showed strong internal consistency for the remaining 19 items (0.93). The internal consistency for each of the six TOCS dimensions also showed high internal consistency with the following Cronbach's alpha values: (1) Cleaning/Contamination: 0.89; (2) Symmetry/Ordering: 0.93; (3) Counting/Checking: 0.89; (4) Rumination: 0.86; (5) Superstition: 0.80; and (6) Hoarding: 0.85. Convergent and Divergent Validity. The TOCS total score showed moderate correlations to both the CBCL-OCS total and weighted scores (both $\mathrm{r}=0.51 ; \mathrm{p} \leq 0.01$ ). The correlation between specific OC dimension scores and the CBCL-OCS scores were variable; Hoarding was the least correlated with the CBCL-OCS $(r=0.27 ; \mathrm{p} \leq 0.001)$ and Rumination the highest $(\mathrm{r}=0.53$ for total score; 
$r=0.54$ for weighted score, both $p \leq 0.001$; see Table 3 ). The TOCS showed a low correlation with the SWAN that was not statistically significant $(r=0.01, p=0.53)$. All the OC dimension scores showed low correlations with the SWAN total score ranging from $r=-0.12$ for Cleaning/Contamination, to $\mathrm{r}=0.13$ for Hoarding (both $\mathrm{p}<0.001$; see Table 3 ). Comparison of TOCS Scores of Reported Disorder Groups. Comparisons of the total TOCS score (range: -63 to +63 ) and TOCS dimension scores (range: -3 to +3 ) among the different reported disorder groups supported the discriminant validity of the TOCS. As seen in Figure 1, the reported OCD group showed the highest mean score of 11.0 (95\%-CI: 7.6 to 14.5 ) compared to the other reported disorder groups. The reported ASD group had the second highest mean TOCS total score of 4.2 (95\%-CI: 1.5 to 7.0). All the other disorder groups displayed mean TOCS total scores below 0. At the dimensional level, discriminant validity did not appear to be as strong as the TOCS total score. The OCD group distinctly showed the highest mean score for the Cleaning/Contamination (mean: 0.3; 95\%-CI: 0.1 to 0.5), Counting/Checking (mean 0.8; 95\%-CI: 0.6 to 1.0 ), Rumination (mean: 1.1; 95\%-CI: 0.9 to 1.4), and Superstition (mean:-0.3; 95\%-CI: -0.5 to -0.1) dimensions (see Figure S1). However, the ASD group showed the highest mean score for the Hoarding (mean: 0.9; 95\%-CI: 0.7 to 1.1 ) and Symmetry/Ordering (mean: 1.1; 95\%-CI: 0.9 to 1.3 ) dimensions. For the Hoarding dimension, all five reported disorder groups showed mean scores higher than 0, with the ASD group showing the highest mean score (mean: $0.9 ; 95 \%-C I: 0.7$ to 1.1 ). When further examined at the item level, we found similar results, with the OCD group scoring the highest for most TOCS items, with the exception of items in the Symmetry/Ordering and Hoarding dimensions in which the ASD group scored higher than the OCD group (see Table S1).

Parent-Child Agreement. In a sub-sample of 332 parent-child pairs where we collected both parent- and self-reported information regarding OC traits, we observed poor agreement between parents and children with ICC values ranging from 0.13 to 0.36 on the TOCS items and total score (Figure 2). The highest ICC values of 0.36 were observed for the "homework" item (95\%-CI: 0.26 to 
$0.45, \mathrm{p}<0.01)$ and the TOCS total score (95\%-CI: 0.23 to $0.46, \mathrm{p}<0.01)$. The lowest ICC of 0.13 (95\%CI: 0.03 to $0.23, \mathrm{p}<0.01$ ) was seen for the "special" item. In general, our Wilcoxon-signed rank tests showed that parents underestimated overall OC traits of their children; parent-reported scores were significantly lower $(\mathrm{p}<0.01)$ than self-reported scores for most items (see Table S2). The differences between parent- and self-reported OC traits were not dependent on whether the items reflected overt or covert behaviours. The only TOCS items where the means of the parent-report was higher than the self-report were "germs", "homework", "dirt", and "ruined."

Sensitivity and Specificity. ROC analyses on the TOCS total score demonstrated an optimal TOCS total cutoff score of $>0$ with sensitivity of 70.7 and specificity of 81.6 in our community sample. The area under the ROC curve (AUC) was 0.83 , indicating good discrimination of OCD cases from non-cases, when using the community-reported diagnosis as a criterion. Sensitivity and specificity were higher in parent than self-respondents (Self-respondent: Cut-off $=0$, Sensitivity $=$ 65 , Specificity $=77$, AUC $=74.2$; Parent-respondent: Cut-off $=2$, Sensitivity $=83$, Specificity $=83$, $\mathrm{AUC}=86.3$ )

Distribution of OC Traits

The distribution of OC traits in our community sample measured by the TOCS total score had skewness and kurtosis statistics of 0.81 and 0.03 , respectively. Compared to the CBCL-OCS total score, which showed a right skew (skewness: 0.81, kurtosis: 0.03 ) with an accumulation at the zero end of the scale (Figure 3a), the distribution measured by the TOCS total score showed a wider distribution of OC traits and more variability at the positive and negative ends of the OC spectrum (Figure 3b). We further examined the distribution of the TOCS at the dimension level, where all dimensions except for the Superstition and Counting/Checking dimensions showed minimal skewness with some accumulation at the negative end (see Figure S2, available online). The skewness and kurtosis statistics, respectively, for each dimension were as follows: 
Cleaning/Contamination $(0.11,-0.46)$, Symmetry/Ordering $(0,-0.76)$, Counting/Checking $(0.28,-$ 0.82), Rumination $(-0.06,-0.81)$, Superstition $(0.48,-0.66)$, and Hoarding $(0,-0.64)$.

In our sample, a total of 140 participants (0.8\%), including 76 males (54.3\%) and 64 females (45.7\%) reported a lifetime diagnosis of OCD. When using the cut-off score of 5 on the CBCL-OCS as a predictor of OCD 21 , a total of 6755 (40.4\%) participants, of which 3291 (48.7\%) were males and 3464 (51.3\%) were females, scored 5 or higher on the CBCL-OCS. Of these individuals, 132 (2\%) of subjects reported a current or previous diagnosis of OCD.

When using the TOCS to examine the prevalence of OC traits (score 2 or 3 on a TOCS item), a total of 7,577 subjects (45.3\%), reported at least one OC trait and 5,254 subjects $(31.4 \%)$ reported at least two OC traits. Despite this high prevalence of OC traits, only 3,150 (18.8\%) individuals of these individuals had a total TOCS score higher than 0 . We observed that some individuals score moderately high across all the TOCS items, resulting in high total TOCS scores; however, most individuals score high on some, while low on other TOCS items resulting in an overall low total TOCS score. For example, among the 7,577 individuals who endorsed at least one OC trait, 5,887 individuals also had at least one low extreme item (score of -2 or -3 on a TOCS item), resulting in a "cancelling out" effect on the total TOCS score.

We further examined OC traits at the dimension level. Some OC traits were more prevalent than others. For example, Symmetry/Ordering, Hoarding, and Cleaning/Contamination traits were more common than other OC dimensions in our sample with $21.4 \%, 19.3 \%$ and $17.2 \%$ of the total number of subjects, respectively, endorsed at least one trait from that OC dimension. Rumination and Counting/Checking traits were less common compared to the other dimensions with $14.6 \%$ and $10.1 \%$ of the sample, respectively endorsing at least one trait. Superstition traits were even less common with only $7.5 \%$ of the sample endorsing at least one trait. No major sex differences were seen in prevalence of OC traits (see Figure S3, available online). 


\section{DISCUSSION}

Trait measures are playing an expanded role in psychiatric research because of increasing awareness that apparently diverse disorders share many characteristics and that these crossdisorder traits might be important to understanding of disease mechanisms and therapeutic discoveries. The TOCS was developed to afford a quick and cost-effective method of measuring the complete distribution of OC traits and dimensions that could be applied in large samples of children and adolescents. The current study evaluated the psychometric properties of the TOCS, and used this novel measure to evaluate the frequency and distribution of OC traits in a large pediatric community sample.

Psychometric Properties of the TOCS

The TOCS demonstrated sound psychometric properties when assessed in over 16,000 children and adolescents aged 6 to 17 years. All items on the TOCS appeared to measure a common set of traits as reflected in its high internal consistency (0.93) as measured by Cronbach's alpha. We propose that these traits collectively reflect the trait of obsessionality and compulsivity that has been proposed to underlie a number of disorders including OCD ${ }^{22}$. Compared to other similar child versions of OC scales, such as the LOI-CV and the OCI-R, which showed internal consistencies of $0.86^{17}$ and $0.85^{16}$, respectively, the TOCS showed excellent cohesiveness in its items. Although very high internal consistency values may present concern for redundancy of items, the face validity and our previous factor analysis (Park et al., under review) support a wide coverage of OC traits as well as the multidimensionality of the TOCS. The high internal consistency values of both the total TOCS items and the items within the six TOCS dimensions support the TOCS as a reliable measure of an overall compulsivity in addition to the different OC dimensions.

We evaluated the concurrent validity of the TOCS by correlating it to the CBCL-OCS, with good reliability and validity, as well as acceptable psychometric properties to assess OCD in 
children $^{23}$. As we expected, the correlations between these two measures were moderate. Although both measures capture OC traits, we likely observed moderate correlations because of the significant differences in the design of the two measures. For example, the TOCS consists of 21 items that cover a wider range of OC traits that are more specific in content, compared with the CBCL-OCS, which only has 8 items that are general in their description. We observed variable correlations between specific TOCS dimensions and CBCL-OCS scores. Most psychometric studies to date have compared self-report OC measures with the CY-BOCS, which is considered as a gold standard measure of OCD. Since the current study aimed to develop an efficient tool to evaluate OC traits in a large sample without conducting clinician-administered questionnaires or interviews, we were unable to use the CY-BOCS and thus, compare the degree of convergent validity.

The current study also supported the divergent validity of the TOCS when evaluated in comparison with a measure of ADHD traits, the SWAN. Our results showed very low correlations between the TOCS and the SWAN, suggesting that the TOCS items discriminated OC traits from those of inattention and hyperactivity. One implication of this finding is that the TOCS is not likely just picking up on general psychopathology but is sensitive to variation in OC traits. When comparing the total TOCS scores among reported disorder groups, the reported OCD group showed the highest mean TOCS scores compared to the other disorder groups supporting the discriminant validity of the TOCS total score.

\section{OC Traits in a Pediatric Community Sample}

In our sample, obsessionality and compulsivity measured by the TOCS and CBCL-OCS total scores were continuously distributed in children and adolescents in the community rather than appearing as dichotomous conditions. The distribution of the CBCL-OCS total scores were skewed to the right as a result of most participants in the community scoring 0 on the narrow rating scale of 0 to 2 on each item of the CBCL-OCS. In contrast, we expected the distribution measured by the 
TOCS to be normally distributed since the TOCS was designed for each item to capture greater variability at both the positive and negative ends of the scale. Although were able to capture a wider variability of the OC traits using the TOCS compared to the CBCL-OCS, the distribution of the total TOCS score also showed a right skew, where more participants than we expected presented with low, or "below average" OC traits (score of 0 or lower). This finding is in contrast to ADHD traits measured by the SWAN, a 7-point scale of ADHD traits similar to the TOCS, which were normally distributed in the same pediatric community sample in previous study by our group ${ }^{24}$. One possible explanation for this skew in the distribution of OC traits is the multidimensional nature of OC traits. We found that some participants scored high on certain items while low on others, which resulted in a low overall total score. When we further examined the distribution of OC traits at the dimension level, most OC dimensions displayed a more normal distribution than the broader OC trait. The one exception was the distribution of the Superstition dimension, which was highly rightskewed. These variable distributions suggest possible differences in the underlying nature, as well as etiology, of the OC dimensions. In support of this hypothesis, we found that in a twin-subset of the larger sample presented in this article, that the heritability of the dimensions showed variable genetic and environmental contributions to each of the OC dimensions (Park et al., under review). In our study reported OC traits were common. Approximately $40 \%$ of participants scored a 5 or higher on the CBCL-OCS ${ }^{21}$ and $45 \%$ of participants endorsed at least one OC trait. Previous population-based studies reported low rates of sub-clinical OCD in children and adolescents (19\%) 7,14 or adolescents and adults $2-25 \% 5,8,11,20,25$. The observed differences in number of OC traits between our study and previous reports may be because we used less stringent criteria to evaluate the prevalence of sub-threshold OC traits. The variability in prevalence rates of subclinical OC traits also reflects the limitation of applying categorical approaches or thresholds in research studies of OCD since the criteria for an "OCD" or "sub-threshold OCD" groups may vary from study to study. 
Our study is the first to examine the full distribution of OC traits both at the overall and dimensional level. Previous studies relied solely on questionnaires like the Obsessive-Compulsive Inventory-Revised, OCI-R; Obsessive Compulsive Scale of the Child Behaviour Checklist, CBCL-OCS; the Child Version of the LOI, LOI-CV; the Brief Obsessive-Compulsive Scale; Children's Florida Obsessive Compulsive Inventory) which were designed as quick screening tools for clinically significant OCD. However, these measures are not ideal for measuring the full and continuous variation in OC traits because of their narrow rating scales (ratings start at 0 ) $23,26-28$. In both research and clinical settings, the "caseness" of OCD is usually determined through a clinical interview when a patient fulfills a criteria guided by the DSM-5, supplemented by cut-off scores on clinician-report instruments, particularly the Yale-Brown Obsessive-Compulsive Scale (YBOCS $)^{29,30}$. However, these categorical groupings may limit research findings as they not only simplify the multidimensional nature of $\mathrm{OCD}^{19,31-33}$ but also overlook any variability that may exist across the whole spectrum of OC traits by omitting individuals with subthreshold OC traits.

Using categorical, instead of continuous trait measures may be particularly problematic in neurobiological and genetic studies. For example, most genetic studies of OCD to date used a dichotomous approach; however, our results demonstrate that OC phenotypes are not only multidimensional, but also quantitative. Although we cannot determine the genetic architecture underlying OC traits until we perform genome-wide analyses, one might speculate based on Plomin et $a .^{3}$, that the underlying genetic architecture for normally distributed traits, such as our Hoarding, Rumination and Symmetry/Ordering dimensions are most likely polygenic. In contrast, other OC dimensions like Superstition may display a more categorical structure and may need an alternate genetic approach. Population-based approaches may also be very helpful for identifying genetic variants associated with categorical psychiatric disorders. For example, a recent study attentiondeficit hyperactivity disorder (ADHD) traits and clinical ADHD shared genetic influences ${ }^{34}$, supporting the importance of using population-based samples to understand the genetic 
architecture of disorders. Moreover, specific types of OC traits have shown to be commonly present in other neurodevelopmental disorders, such as ASD ${ }^{35}$, suggesting possible shared etiology across disorders. Since some OC dimensions may not only be specific to OCD but also span across disorders, the dimensional model provides the advantage to examine neurobiological and genetic correlates beyond categorical diagnoses in much larger samples. Therefore, using a measure like the TOCS that captures the full phenotypic variation of OC traits and its dimensions will be immensely helpful to identify neurobiological and genetic mechanisms involved in OCD and OC traits.

We also demonstrated high overlap in OC traits between the community-reported psychiatric disorder groups. Although our findings indicated that the total TOCS score and most dimension scores are able to distinguish the OCD group from other psychiatric disorder groups, some dimension scores were comparable. In particular, individuals with reported ASD showed comparable scores on the Hoarding and Symmetry/Ordering to the OCD group, suggesting that these two dimensions encompass traits that are highly shared between the two disorders. In support of the dimensional approach of psychiatric disorders, it is not surprising that OC traits are also present in other disorder groups, particularly disorders known to be comorbid with OCD like ASD 36-38. Scores from the hoarding dimension also tended to be higher across the various community-reported diagnosis groups which suggests that this dimension may be tapping in to more general psychopathology and not just OCD, a finding consistent with the creation of hoarding disorder in DSM-539 (REF). Nevertheless, we did not control for comorbid disorders in our comparisons of the total and dimensional TOCS scores in our study. Therefore, the high comorbidity between OCD and other psychiatric disorder may have contributed to the elevated TOCS score. Examining OC traits at the dimensional level and beyond the silos of current disorder groups may shed light to etiological mechanisms that are not only specific to a disorder, but also shared across disorders. 
There are a few limitations to our study. We were not able to clinically validate the community reported diagnoses; however, prevalence rates of disorders like ADHD, OCD and anxiety were similar to previous studies ${ }^{7,40,41}$ (Reis Merikangas et al., 2009). Furthermore, our data was cross-sectional and most of the phenotypic data relied on reported information from either the participants or their parents. Our analyses showed low parent-child agreement on the TOCS in a small subset of our sample, which demonstrates the need for collecting data from multiple informants in future studies. However, parent-ratings had better sensitivity and specificity than child-ratings. With the above limitations in mind, further investigation in other samples of children and adolescents using a similar research framework as the current study is necessary to replicate and confirm our findings. For example, our sample collected at the Ontario Science Centre may not reflect the larger pediatric population. Therefore, additional studies in various regions would be informative. One of the main advantages of the current study is that we have collected cognitive and genetic data from all our subjects, which allows us to examine the full cognitive and genetic variability underlying the OC phenotypic variation. More importantly, this study provides a better understanding of OC traits in the general pediatric community, emphasizing the importance of a quantitative, dimensional approach in genetic and neurobiological studies of OC traits.

Compared to previously developed OC scales, the TOCS is a reliable, dimensional measure of OC traits with the following advantages: (1) a scale which allows the measurement of a wider distribution of OC traits; (2) items which comprise a comprehensive, multidimensional measure of OC traits; and (3) a way to collect information from both children and parents. In conclusion, the TOCS demonstrated sound psychometric properties. Our findings have important implications in future OCD research and in establishing biomarkers according to the RDoC framework. First, OC traits are present beyond the nosological boundaries of OCD. By expanding research beyond individuals with an OCD diagnosis to the general community, we were able to examine the whole phenotypic variation of OC traits, which includes individuals at the extreme low end of the OC 
spectrum who may display biologically relevant behaviours such as resilience. Second, the use of TOCS in a large community sample would not only increase statistical power but also provide insight into a wider phenotypic and genetic variability present in the community. An important implication of our study from a clinical perspective is that a dimensional approach to neurobiological and genetic studies may inform us with regards to the etiology of OC traits, which in turn, may inform the diagnostic criteria for OCD in the future.

\section{REFERENCES}

1. Hudziak JJ, Achenbach TM, Althoff RR, Pine DS. A dimensional approach to developmental psychopathology. Int. J. Methods Psychiatr. Res. 2007;16 Suppl 1:S16-23.

2. van der Sluis S, Posthuma D, Nivard MG, Verhage M, Dolan CV. Power in GWAS: lifting the curse of the clinical cut-off. Molecular Psychiatry. 2013;18(1):2-3.

3. Plomin R, Haworth CMA, Davis OSP. Common disorders are quantitative traits. Nat. Rev. Genet. 2009;10(12):872-878.

4. Fineberg NA, Hengartner MP, Bergbaum C, Gale T, Rössler W, Angst J. Lifetime comorbidity of obsessive-compulsive disorder and sub-threshold obsessive-compulsive symptomatology in the community: impact, prevalence, socio-demographic and clinical characteristics. Int J Psychiatry Clin Pract. 2013;17(3):188-196.

5. de Bruijn C, Beun S, de Graaf R, Have ten M, Denys D. Subthreshold symptoms and obsessivecompulsive disorder: evaluating the diagnostic threshold. Psychological Medicine. 2010;40(6):989997.

6. Adam Y, Meinlschmidt G, Gloster AT, Lieb R. Obsessive-compulsive disorder in the community: 12-month prevalence, comorbidity and impairment. Soc Psychiatry Psychiatr Epidemiol.

2012;47(3):339-349. 
7. Valleni-Basile LA, Garrison CZ, Jackson KL, et al. Frequency of obsessive-compulsive disorder in a community sample of young adolescents. JAAC. 1994;33(6):782-791.

8. Angst J, Gamma A, Endrass J, et al. Obsessive-compulsive severity spectrum in the community: prevalence, comorbidity, and course. Eur Arch. 2004;254(3):156-164.

9. Apter A, Fallon TJ, King RA, et al. Obsessive-compulsive characteristics: from symptoms to syndrome. JAAC. 1996;35(7):907-912.

10. Maina G, Albert U, Bogetto F, Ravizza L. Obsessive-compulsive syndromes in older adolescents. acta psychiatrica Scandinavica. 1999;100(6):447-450.

11. Fullana MA, Mataix-Cols D, Caspi A, et al. Obsessions and compulsions in the community: prevalence, interference, help-seeking, developmental stability, and co-occurring psychiatric conditions. American Journal of Psychiatry. 2009;166(3):329-336.

12. Voltas N, Hernández-Martínez C, Arija V, Aparicio E, Canals J. A prospective study of paediatric obsessive-compulsive symptomatology in a Spanish community sample. Child Psychiatry Hum Dev. 2014;45(4):377-387.

13. Grabe H-J, Meyer C, Hapke U, et al. Prevalence, quality of life and psychosocial function in obsessive-compulsive disorder and subclinical obsessive-compulsive disorder in northern Germany. Eur Arch. 2000;250(5):262-268.

14. Vivan A de S, Rodrigues L, Wendt G, Bicca MG, Braga DT, Cordioli AV. Obsessive-compulsive symptoms and obsessive-compulsive disorder in adolescents: a population-based study. Rev Bras Psiquiatr. 2014;36(2):111-118.

15. Kim M-S, Jang K-M, Kim B-N. The neuropsychological profile of a subclinical obsessivecompulsive sample. J Int Neuropsychol Soc. 2009;15(2):286-290.

16. Foa EB, Coles M, Huppert JD, Pasupuleti RV, Franklin ME, March J. Development and validation of a child version of the obsessive compulsive inventory. Behav Ther. 2010;41(1):121-132.

17. Bamber D, Tamplin A, Park RJ, Kyte ZA, Goodyer IM. Development of a short leyton obsessional inventory for children and adolescents. JAAC. 2002;41(10):1246-1252.

18. Berg CZ, Whitaker A, Davies M, Flament MF, Rapoport JL. The survey form of the Leyton Obsessional Inventory-Child Version: norms from an epidemiological study. JAAC. 1988;27(6):759763.

19. Bloch MH, Landeros-Weisenberger A, Rosario MC, Pittenger C, Leckman JF. Meta-analysis of the symptom structure of obsessive-compulsive disorder. American Journal of Psychiatry. 2008;165(12):1532-1542.

20. Nelson EC, Hanna GL, Hudziak JJ, Botteron KN, Heath AC, Todd RD. Obsessive-compulsive scale of the child behavior checklist: specificity, sensitivity, and predictive power. Pediatrics. 2001;108(1):E14.

21. Hudziak JJ, Althoff RR, Stanger C, et al. The Obsessive Compulsive Scale of the Child Behavior Checklist predicts obsessive-compulsive disorder: a receiver operating characteristic curve 
analysis. J Child Psychol Psychiatry. 2006;47(2):160-166.

22. Robbins TW, Gillan CM, Smith DG, de Wit S, Ersche KD. Neurocognitive endophenotypes of impulsivity and compulsivity: towards dimensional psychiatry. Trends Cogn. Sci. (Regul. Ed.). 2012;16(1):81-91.

23. Geller DA, Doyle R, Shaw D, et al. A quick and reliable screening measure for OCD in youth: reliability and validity of the obsessive compulsive scale of the Child Behavior Checklist. Comprehensive Psychiatry. 2006;47(3):234-240.

24. Crosbie J, Arnold P, Paterson A, et al. Response inhibition and ADHD traits: correlates and heritability in a community sample. Journal of Abnormal Child Psychology. 2013;41(3):497-507.

25. Bryńska A, Wolańczyk T. Epidemiology and phenomenology of obsessive-compulsive disorder in non-referred young adolescents: a Polish perspective. Eur Child Adolesc Psychiatry. 2005;14(6):319-327.

26. Grabill K, Merlo L, Duke D, et al. Assessment of obsessive-compulsive disorder: a review. Journal of Anxiety Disorders. 2008;22(1):1-17.

27. Bejerot S, Edman G, Anckarsäter H, et al. The Brief Obsessive-Compulsive Scale (BOCS): A selfreport scale for OCD and obsessive-compulsive related disorders. Nord J Psychiatry. 2014:1-11.

28. Storch EA, Khanna M, Merlo LJ, et al. Children's Florida Obsessive Compulsive Inventory: psychometric properties and feasibility of a self-report measure of obsessive-compulsive symptoms in youth. Child Psychiatry Hum Dev. 2009;40(3):467-483.

29. Scahill L, Riddle MA, McSwiggin-Hardin M, et al. Children's Yale-Brown Obsessive Compulsive Scale: reliability and validity. JAAC. 1997;36(6):844-852.

30. Goodman WK. The Yale-Brown Obsessive Compulsive ScaleI. Development, Use, and Reliability. Arch. Gen. Psychiatry. 1989;46(11):1006.

31. Moore J, Smith GW, Shevlin M, O'Neill FA. Alternative factor models and heritability of the Short Leyton Obsessional Inventory-Children's Version. Journal of Abnormal Child Psychology. 2010;38(7):921-934.

32. Iervolino AC, Rijsdijk FV, Cherkas L, Fullana MA, Mataix-Cols D. A multivariate twin study of obsessive-compulsive symptom dimensions. Arch. Gen. Psychiatry. 2011;68(6):637-644.

33. van Grootheest DS, Boomsma DI, Hettema JM, Kendler KS. Heritability of obsessive-compulsive symptom dimensions. Am. J. Med. Genet. B Neuropsychiatr. Genet. 2008;147B(4):473-478.

34. Stergiakouli E, Martin J, Hamshere ML, et al. Shared genetic influences between attentiondeficit/hyperactivity disorder (ADHD) traits in children and clinical ADHD. J Am Acad Child Adolesc Psychiatry. 2015;54(4):322-327.

35. Jacob S, Landeros-Weisenberger A, Leckman JF. Autism spectrum and obsessive-compulsive disorders: OC behaviors, phenotypes and genetics. Autism Res. 2009;2(6):293-311.

36. Fineberg NA, Baldwin DS, Menchon JM, et al. Manifesto for a European research network into 
obsessive-compulsive and related disorders. Eur Neuropsychopharmacol. 2013;23(7):561-568.

37. Ruta L, Mugno D, D'Arrigo VG, Vitiello B, Mazzone L. Obsessive-compulsive traits in children and adolescents with Asperger syndrome. Eur Child Adolesc Psychiatry. 2010;19(1):17-24.

38. Russell AJ, Mataix-Cols D, Anson M, Murphy DGM. Obsessions and compulsions in Asperger syndrome and high-functioning autism. Br J Psychiatry. 2005;186:525-528.

39. American Psychiatric Association. Diagnostic and Statistical Manual of Mental Disorders, Fifth Edition (DSM-5). American Psychiatric Publishing; 2013.

40. Flament MF, Whitaker A, Rapoport JL, et al. Obsessive compulsive disorder in adolescence: an epidemiological study. J Am Acad Child Adolesc Psychiatry. 1988,27:764-771.

41. Merikangas KR, Nakmura EF, Kessler RC. Epidemiology of mental disorders in children and adolescents. Dialogues Clin Neurosci. 2009; 11:7-20.

\section{TABLES}


Table 1. Demographic Information of the Total Community Sample $(N=16,718)$. The prevalence of community-reported disorders were based on either self- or parent-reported information. Freq = frequency; ADHD: Attention-Deficit/Hyperactivity Disorder; Anxiety: any Anxiety Disorder; ASD: Autism Spectrum Disorder; OCD: Obsessive-Compulsive Disorder.

\begin{tabular}{rccc}
\hline & $\begin{array}{c}\text { Total } \\
(\mathrm{N}=16,718)\end{array}$ & $\begin{array}{c}\text { Males } \\
(\mathrm{n}=8,447)\end{array}$ & $\begin{array}{c}\text { Females } \\
(\mathrm{n}=8,271)\end{array}$ \\
\hline $\begin{array}{r}\text { Mean Age in years (+/-SD) } \\
\text { Respondent (Freq, \%) }\end{array}$ & $11.1(+/-2.8)$ & $10.8(+/-2.7)$ & $11.3(+/-3.0)$ \\
Self-Report & $3,038(18.2 \%)$ & $1,198(14.2 \%)$ & $1,840(22.2 \%)$ \\
Parent-Report & $13,680(81.8 \%)$ & $7,249(85.8 \%)$ & $6,431(77.8 \%)$ \\
White ethnicity (Freq, \%) & $8,615(51.5 \%)$ & $4,453(52.7 \%)$ & $4,162(50.3 \%)$ \\
Reported Disorders (Freq, \%) & & & \\
ADHD & $1,026(6.1 \%)$ & $749(8.9 \%)$ & $277(3.3 \%)$ \\
Anxiety & $578(3.5 \%)$ & $305(3.6 \%)$ & $273(3.3 \%)$ \\
ASD & $222(1.3 \%)$ & $190(2.2 \%)$ & $32(0.4 \%)$ \\
Depression & $196(1.2 \%)$ & $94(1.1 \%)$ & $102(1.2 \%)$ \\
Tics & $192(1.2 \%)$ & $137(1.6 \%)$ & $55(0.7 \%)$ \\
OCD & $140(0.8 \%)$ & $76(0.9 \%)$ & $64(0.8 \%)$ \\
Schizophrenia/Bipolar & $16(0.1 \%)$ & $9(0.1 \%)$ & $7(0.1 \%)$ \\
\hline
\end{tabular}


Table 2. Summary of Obsessive-Compulsive (OC) Dimensions and Related Items from the Toronto Obsessive-Compulsive Scale (TOCS)

\begin{tabular}{ll}
\hline Factors & Items \\
\hline Counting/Checking & Need to do certain things (e.g., counting \\
steps) & Check things \\
& Needs to count objects \\
Cleaning/Contamination & Hate dirt/dirty things \\
& Worry about germs \\
& Need to wash hands \\
& Worry about being clean \\
& Someone using/touching something ruins it \\
& Collects useless objects \\
& Difficulty throwing away \\
Hoarding & Things need to be symmetrical \\
& Gets upset when people rearrange things \\
Symmetry/Ordering & Repeats actions till just right \\
& Worry if you do something not exactly right \\
& Have special numbers or words \\
& Do certain things to avoid bad luck \\
& Worry about having an illness or disease \\
Superstition & Feels guilty about doing something wrong \\
& Keep thinking about things you've done \\
Rumination & Upsetting unwanted thoughts \\
& Checking and rechecking homework \\
Unclassified &
\end{tabular}


Table 3. Internal consistency of the Toronto Obsessive Compulsive Scale (TOCS) and its correlations with the Obsessive Compulsive Scale of the Child Behaviour Checklist (CBCLOCS) and the Strengths and Weaknesses of ADHD Symptoms and Normal Behaviour Rating Scale (SWAN). All correlations were significant at $\mathrm{p} \leq 0.001$ with the exception in

\begin{tabular}{|c|c|c|c|c|}
\hline & $\begin{array}{c}\text { Internal } \\
\text { Consistency }\end{array}$ & \multicolumn{2}{|c|}{ Spearman's Correlations } & $\begin{array}{c}\text { Pearson's Correlation } \\
(p-v a l u e)\end{array}$ \\
\hline & Cronbach's Alpha & $\begin{array}{c}\text { CBCL-OCS } \\
\text { Total Score }\end{array}$ & $\begin{array}{c}\text { CBCL-OCS } \\
\text { Weighted Score }\end{array}$ & SWAN Total Score \\
\hline TOCS Total & 0.94 & 0.51 & 0.51 & $0.01(0.53)$ \\
\hline $\begin{array}{l}\text { TOCS Total } \\
(19 \text { items })^{\mathrm{a}}\end{array}$ & 0.93 & 0.51 & 0.51 & $0.01(0.12)$ \\
\hline $\begin{array}{l}\text { Cleaning/ } \\
\text { Contamination } \\
\text { (5 items) }\end{array}$ & 0.89 & 0.34 & 0.34 & -0.12 \\
\hline $\begin{array}{l}\text { Symmetry/ } \\
\text { Ordering } \\
\text { (4 items) }\end{array}$ & 0.86 & 0.49 & 0.49 & $-0.01(0.87)$ \\
\hline $\begin{array}{l}\text { Counting/ } \\
\text { Checking } \\
\text { (3 items) }\end{array}$ & 0.80 & 0.41 & 0.41 & 0.08 \\
\hline $\begin{array}{l}\text { Rumination } \\
\text { ( } 2 \text { items) }\end{array}$ & 0.85 & 0.53 & 0.54 & $-0.01(0.94)$ \\
\hline $\begin{array}{l}\text { Superstition } \\
\text { ( } 3 \text { items) }\end{array}$ & 0.80 & 0.37 & 0.37 & 0.07 \\
\hline $\begin{array}{l}\text { Hoarding } \\
\text { (2 items) }\end{array}$ & 0.82 & 0.27 & 0.27 & 0.13 \\
\hline
\end{tabular}




\section{FIGURES}

Figure 1. Discriminant Validity of the Toronto Obsessive-Compulsive Scale (TOCS). The mean TOCS total score between the reported disorder groups. 95\% confidence intervals (CI) are shown. OCD: obsessive-compulsive disorder; ASD: autism spectrum disorder; ANX: any anxiety disorder; TICS: tic disorder; ADHD: attention-deficit/hyperactivity disorder; No Dx: no reported disorder.

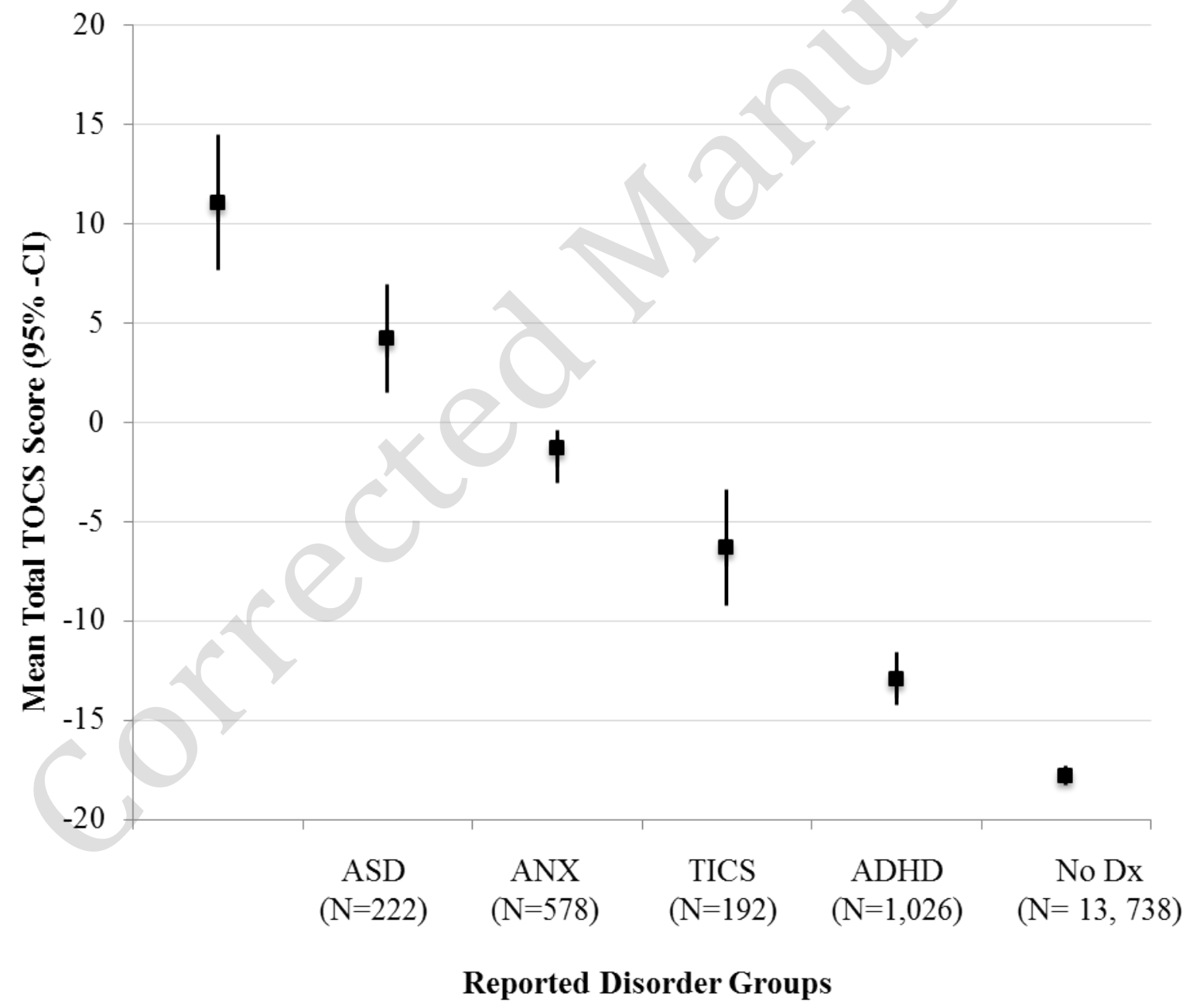


Figure 2. Parent-Child Agreement on the Toronto Obsessive-Compulsive Scale (TOCS; n=332

pairs). The intra-class correlations (ICC) on the TOCS between parent- and child self-reported scores are shown with 95\% confidence intervals (CI). The items are arranged from highest to lowest agreement (ICC values). The "interfere" item on the TOCS was excluded from analysis since we had incomplete information on the item as it was missing in the paper versions of the questionnaires.

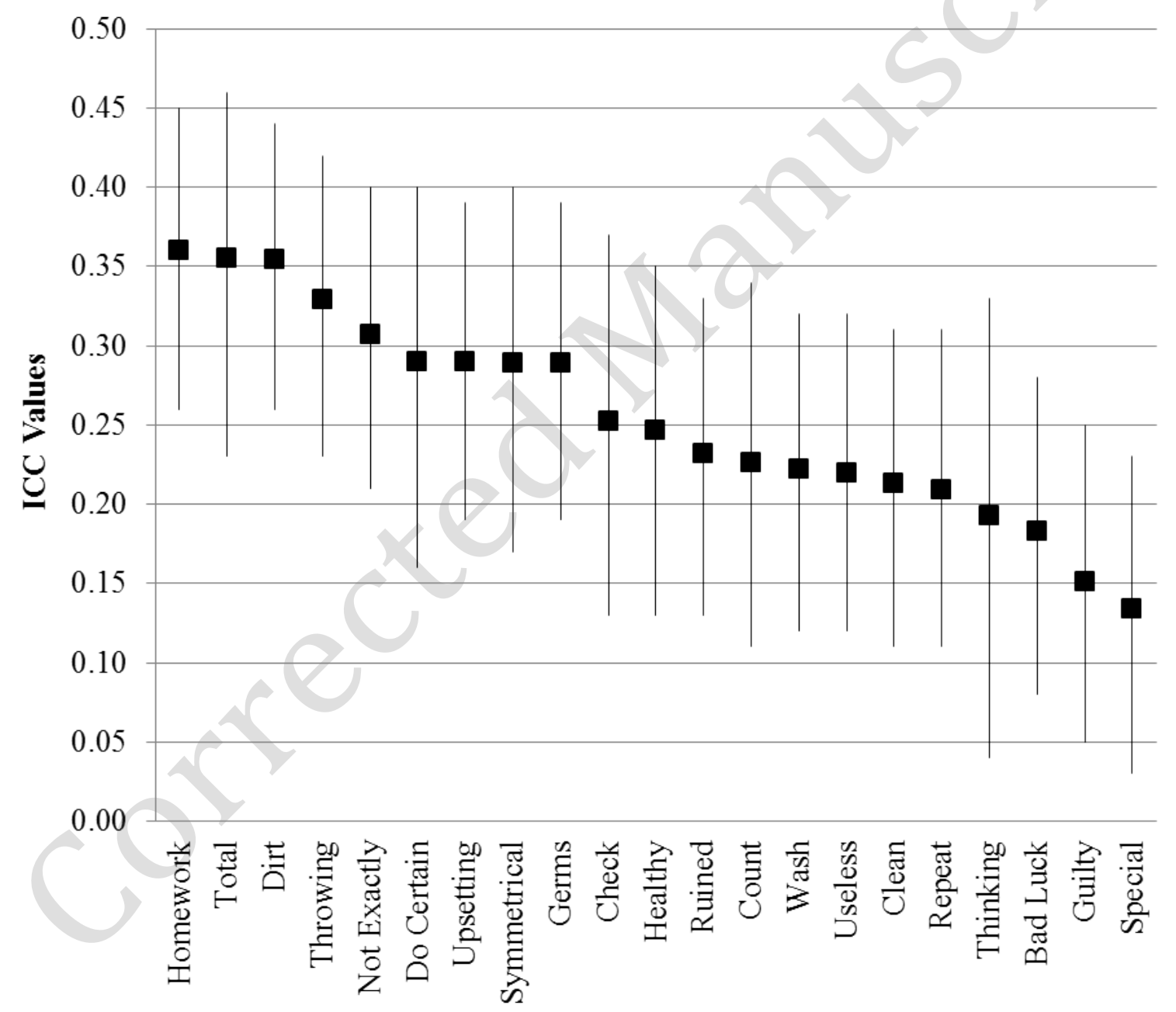

TOCS Items 
Figure 3. Distribution of Obsessive-Compulsive (OC) Traits. a) The distribution of OC traits measured by the obsessive-compulsive scale of the Child Behaviour Checklist (CBCL-OCS) total score was plotted and a normality curve was fitted to the data. b) The distribution of OC traits measured by the Toronto Obsessive-Compulsive Scale (TOCS) Total Score was plotted and a normality curve was fitted to the data.

a)

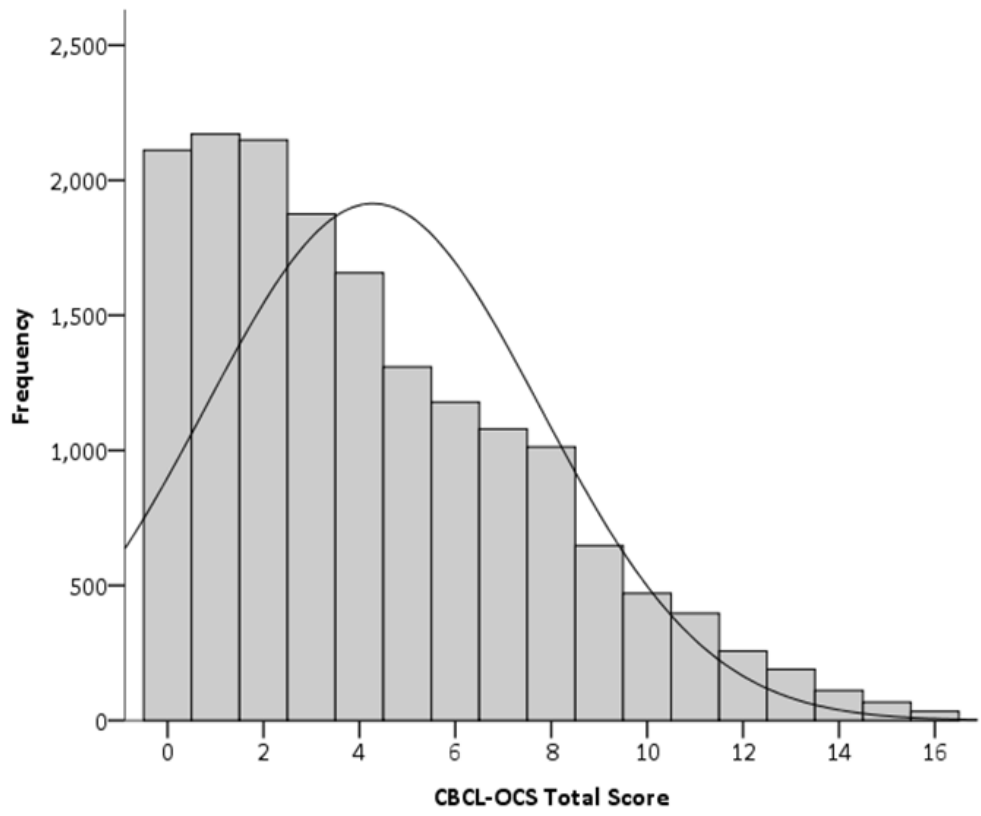

b)

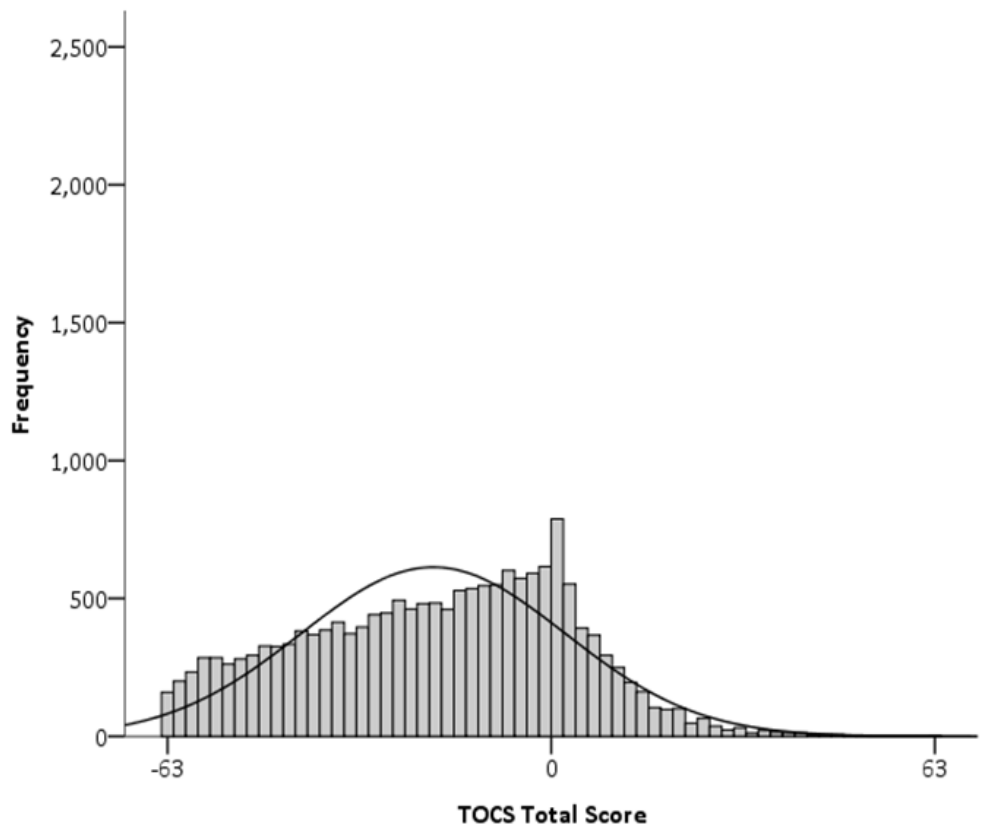


Figure 4. Percentage of Participants with OC traits as measured by the Toronto Obsessive-

Compulsive Scale (TOCS). Percentage of individuals with a score of 2 or 3 on an item on the TOCS is shown. The boxes include TOCS items belonging to their respective TOCS dimension.

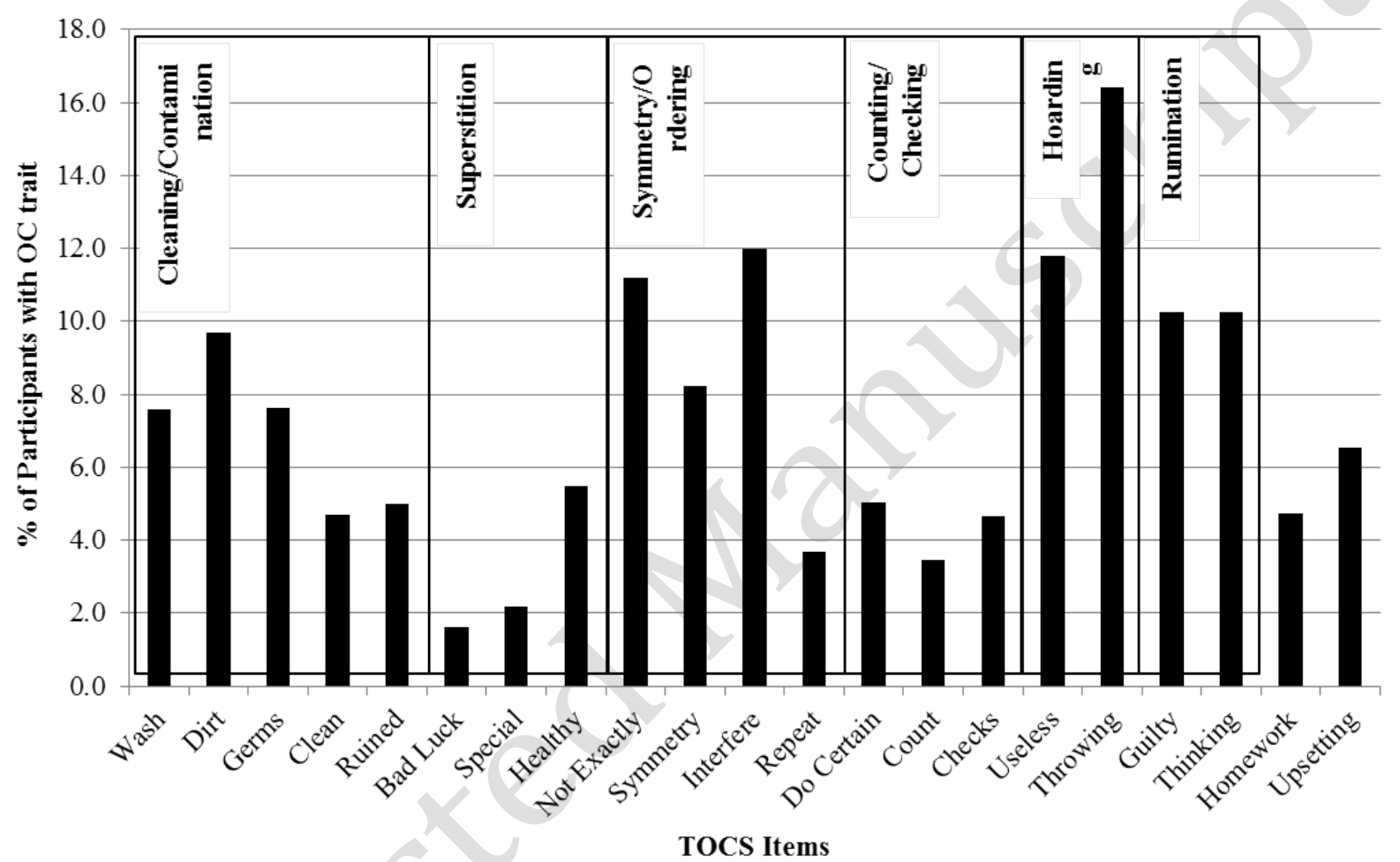


Figure S1. Discriminant Validity of the Obsessive-Compulsive (OC) Dimensions. The mean OC dimension scores between the reported disorder groups are shown with 95\% confidence intervals (CI). The dashed line represents a mean score of zero. OCD: obsessive-compulsive disorder; TICS: tic disorder; ADHD: attention-deficit/hyperactivity disorder; ANX: any anxiety disorder; ASD: autism spectrum disorder.

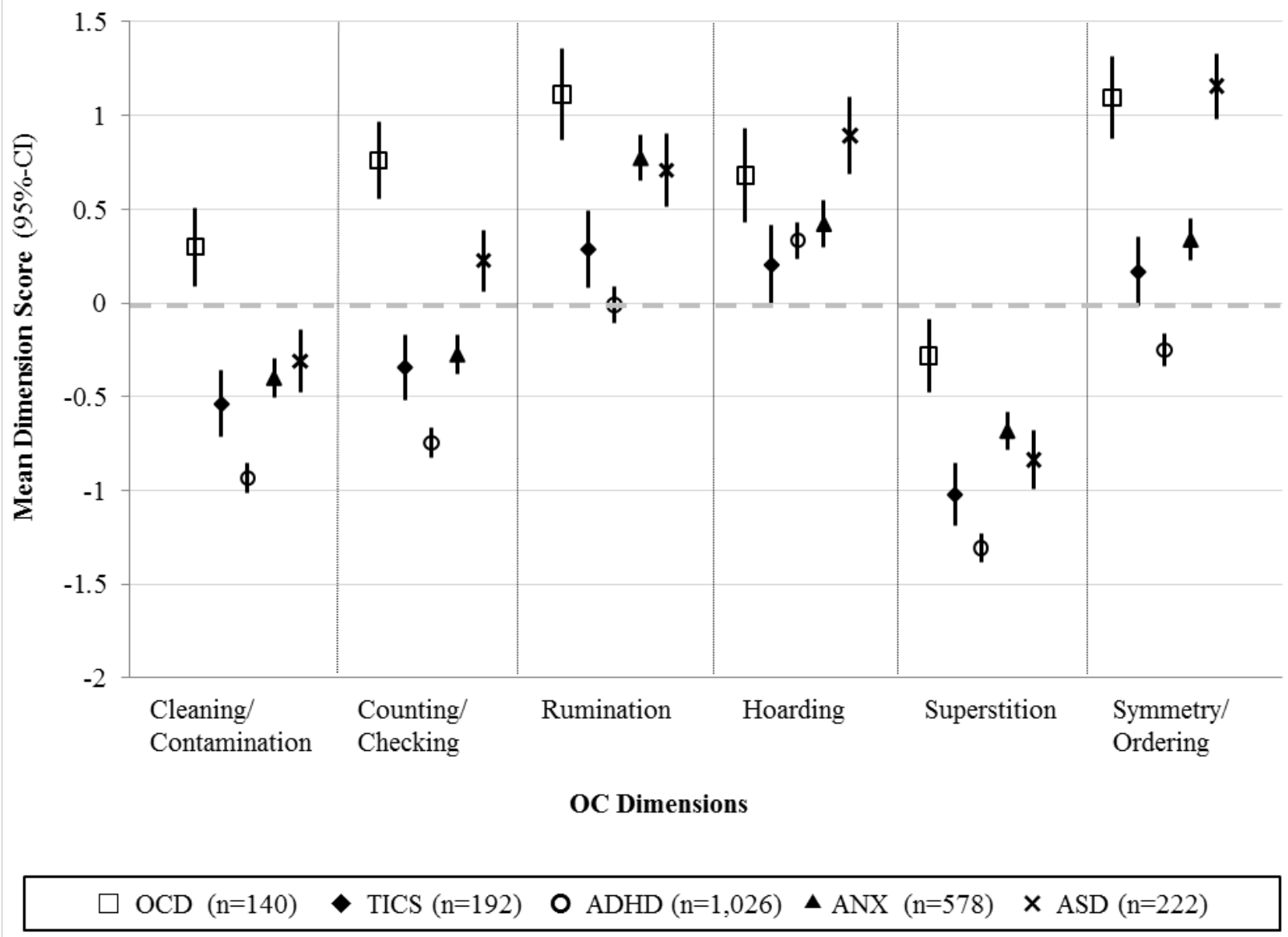

Figure S2. Distribution of the Obsessive-Compulsive (OC) Dimensions of the Toronto Obsessive-Compulsive Scale (TOCS). The normal curve was fitted to the data as shown. Most OC 
dimensions showed a normal distribution with a slight left skew except for the Superstition and Counting/Checking dimensions.
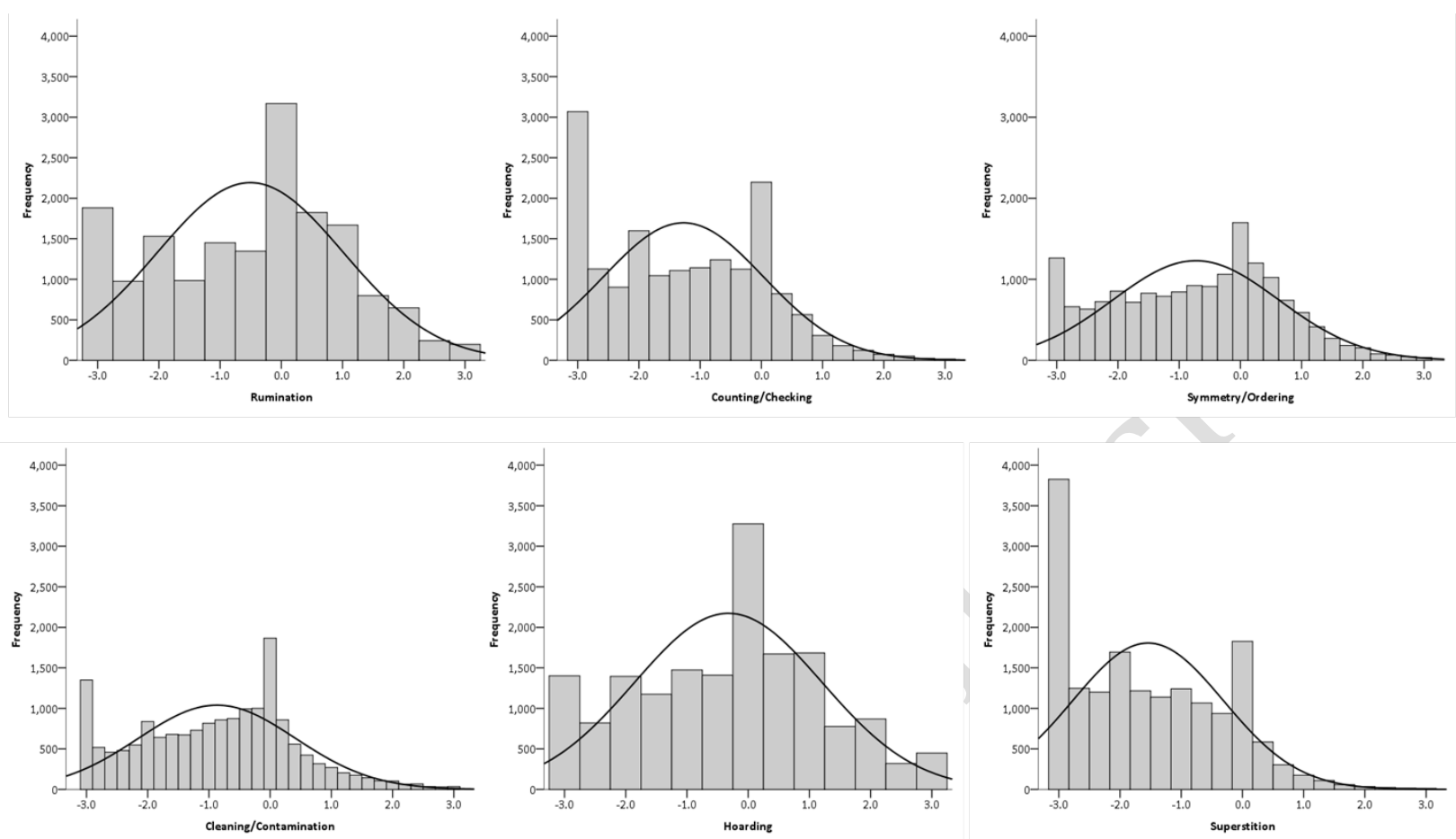
Figure S3. Percentage of Participants with OC traits by Sex. Number of participants with a score of a 2 or 3 on an item on the Toronto Obsessive-Compulsive Scale(TOCS) distributed by sex. Each of the boxes show the TOCS dimension as labeled.

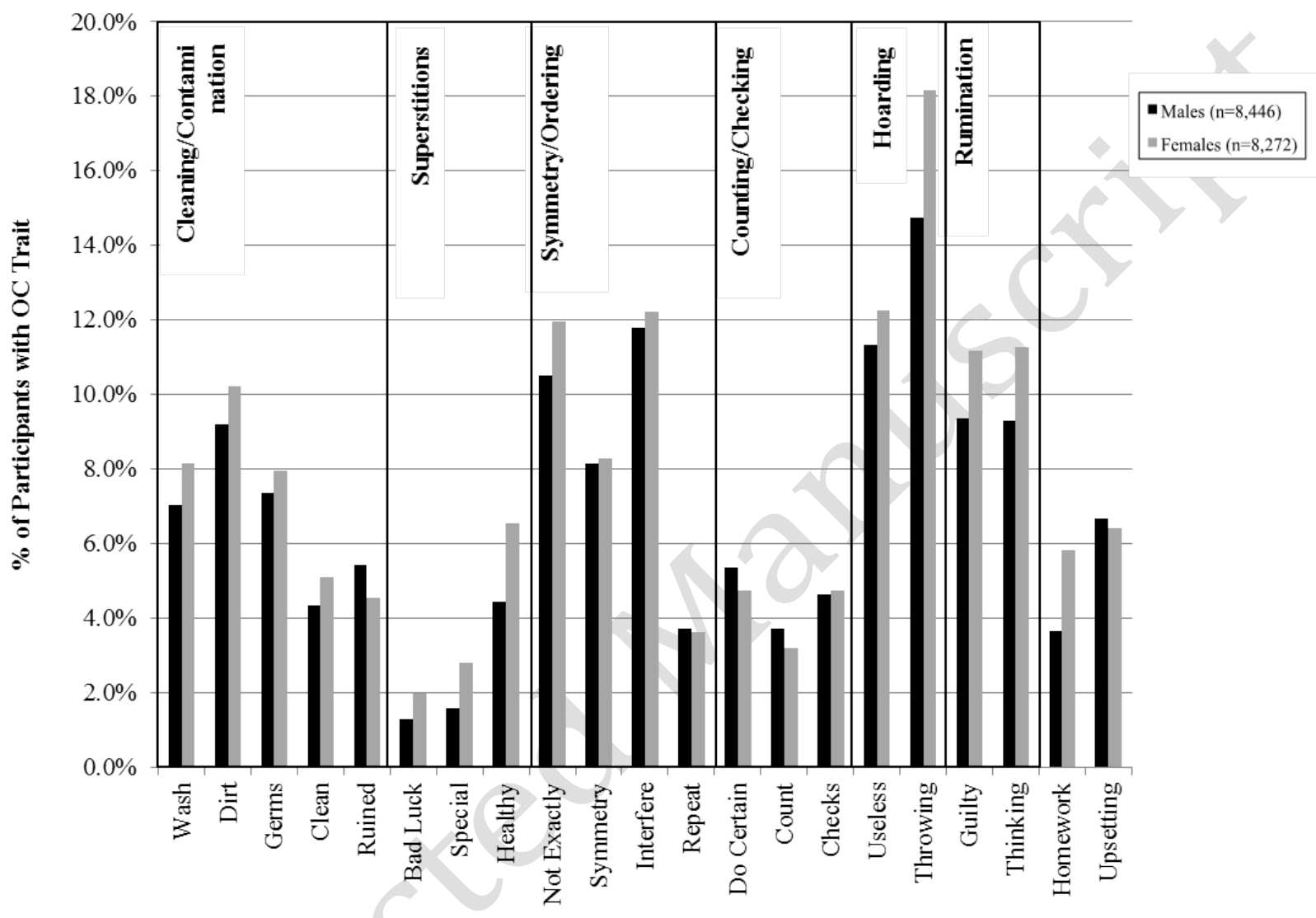

TOCS Items 
Table S1. Mean score on each Toronto Obsessive Compulsive Scale (TOCS) items for the community-reported disorder groups. OCD: obsessive-compulsive disorder; ADHD: attentiondeficit/hyperactivity disorder; ANX: any anxiety disorder; ASD: autism spectrum disorder; CI: confidence

\begin{tabular}{|c|c|c|c|c|c|c|}
\hline \multirow{2}{*}{ TOCS Items } & & \multicolumn{5}{|c|}{ Reported Diagnosis } \\
\hline & & OCD & TICS & ADHD & ANX & ASD \\
\hline \multicolumn{7}{|c|}{ Cleaning/Contamination } \\
\hline & mean & 0.28 & 0.13 & 0.08 & 0.16 & 0.15 \\
\hline 1. Germs & $95 \%-C I$ & $(0.21-0.37)$ & $\begin{array}{c}(0.09- \\
0.19)\end{array}$ & $\begin{array}{c}(0.06- \\
0.10)\end{array}$ & $\begin{array}{l}(0.13- \\
0.19)\end{array}$ & $\begin{array}{l}(0.11- \\
0.21)\end{array}$ \\
\hline & mean & 0.31 & 0.14 & 0.07 & 0.13 & 0.12 \\
\hline 2. Wash & $95 \%-C I$ & $(0.23-0.39)$ & $\begin{array}{c}(0.10- \\
0.21)\end{array}$ & $\begin{array}{c}(0.06- \\
0.10)\end{array}$ & $\begin{array}{l}(0.10- \\
0.16)\end{array}$ & $\begin{array}{c}(0.08- \\
0.18)\end{array}$ \\
\hline & mean & 0.25 & 0.07 & 0.05 & 0.10 & 0.08 \\
\hline 3. Clean & $95 \%-C I$ & $(0.18-0.34)$ & $\begin{array}{c}(0.04- \\
0.12)\end{array}$ & $\begin{array}{c}(0.04- \\
0.07)\end{array}$ & $\begin{array}{l}(0.08- \\
0.13)\end{array}$ & $\begin{array}{l}(0.04- \\
0.13)\end{array}$ \\
\hline 4. Dirt & $\begin{array}{c}\text { mean } \\
95 \%-C I\end{array}$ & $\begin{array}{c}0.31 \\
(0.23-0.40)\end{array}$ & $\begin{array}{c}0.18 \\
(0.13- \\
0.25)\end{array}$ & $\begin{array}{c}0.11 \\
(0.09- \\
0.13)\end{array}$ & $\begin{array}{c}0.17 \\
(0.14- \\
0.21)\end{array}$ & $\begin{array}{c}0.23 \\
(0.17- \\
0.30)\end{array}$ \\
\hline 5. Ruined & $\begin{array}{c}\text { mean } \\
95 \%-C I\end{array}$ & $\begin{array}{c}0.26 \\
(0.19-0.35)\end{array}$ & $\begin{array}{c}0.12 \\
(0.08- \\
0.17)\end{array}$ & $\begin{array}{c}0.08 \\
(0.06- \\
0.10)\end{array}$ & $\begin{array}{c}0.12 \\
(0.09- \\
0.15)\end{array}$ & $\begin{array}{c}0.18 \\
(0.13- \\
0.25)\end{array}$ \\
\hline \multicolumn{7}{|c|}{ Symmetry/Ordering } \\
\hline 6. Symmetry & $\begin{array}{l}\text { mean } \\
95 \%-C I\end{array}$ & $\begin{array}{c}0.41 \\
(0.32-0.50)\end{array}$ & $\begin{array}{c}0.20 \\
(0.14- \\
0.27)\end{array}$ & $\begin{array}{c}0.14 \\
(0.12- \\
0.17)\end{array}$ & $\begin{array}{c}0.21 \\
(0.17- \\
0.25)\end{array}$ & $\begin{array}{c}0.44 \\
(0.37- \\
0.52)\end{array}$ \\
\hline 7. Repeat & $\begin{array}{c}\text { mean } \\
95 \%-C I\end{array}$ & $\begin{array}{c}0.32 \\
(0.24-0.42)\end{array}$ & $\begin{array}{c}0.15 \\
(0.10- \\
0.22)\end{array}$ & $\begin{array}{c}0.09 \\
(0.07- \\
0.12)\end{array}$ & $\begin{array}{c}0.14 \\
(0.11- \\
0.18)\end{array}$ & $\begin{array}{c}0.27 \\
(0.20- \\
0.35)\end{array}$ \\
\hline 8. Interfere & $\begin{array}{c}\text { mean } \\
95 \%-C I\end{array}$ & $\begin{array}{c}0.46 \\
(0.37-0.54)\end{array}$ & $\begin{array}{c}0.29 \\
(0.23- \\
0.37)\end{array}$ & $\begin{array}{c}0.24 \\
(0.21- \\
0.27)\end{array}$ & $\begin{array}{c}0.32 \\
(0.27- \\
0.36)\end{array}$ & $\begin{array}{c}0.62 \\
(0.55- \\
0.69)\end{array}$ \\
\hline $\begin{array}{l}\text { 9. Not } \\
\text { Exactly }\end{array}$ & $\begin{array}{l}\text { mean } \\
95 \%-C I\end{array}$ & $\begin{array}{c}0.55 \\
(0.46-0.55)\end{array}$ & $\begin{array}{c}0.31 \\
(0.24- \\
0.38)\end{array}$ & $\begin{array}{c}0.25 \\
(0.22- \\
0.28)\end{array}$ & $\begin{array}{c}0.42 \\
(0.37- \\
0.47)\end{array}$ & $\begin{array}{c}0.54 \\
(0.46- \\
0.61)\end{array}$ \\
\hline \multicolumn{7}{|l|}{ Superstition } \\
\hline 10. Bad Luck & $\begin{array}{c}\text { mean } \\
95 \%-C I\end{array}$ & $\begin{array}{c}0.11 \\
(0.07-0.18)\end{array}$ & $\begin{array}{c}0.07 \\
(0.04- \\
0.12)\end{array}$ & $\begin{array}{c}0.03 \\
(0.02- \\
0.04)\end{array}$ & $\begin{array}{c}0.06 \\
(0.04- \\
0.08)\end{array}$ & $\begin{array}{c}0.09 \\
(0.05- \\
0.15)\end{array}$ \\
\hline 11. Special & $\begin{array}{c}\text { mean } \\
95 \%-C I\end{array}$ & $\begin{array}{c}0.13 \\
(0.08-0.20)\end{array}$ & $\begin{array}{c}0.07 \\
(0.04- \\
0.12)\end{array}$ & $\begin{array}{c}0.04 \\
(0.02- \\
0.05)\end{array}$ & $\begin{array}{c}0.06 \\
(0.04- \\
0.09)\end{array}$ & $\begin{array}{c}0.06 \\
(0.03- \\
0.12)\end{array}$ \\
\hline 12. Healthy & $\begin{array}{c}\text { mean } \\
95 \%-C I\end{array}$ & $\begin{array}{c}0.24 \\
(0.17-0.32)\end{array}$ & $\begin{array}{c}0.17 \\
(0.12- \\
0.24)\end{array}$ & $\begin{array}{c}0.09 \\
(0.07- \\
0.11)\end{array}$ & $\begin{array}{c}0.22 \\
(0.18- \\
0.26)\end{array}$ & $\begin{array}{c}0.17 \\
(0.12- \\
0.24)\end{array}$ \\
\hline
\end{tabular}




\begin{tabular}{|c|c|c|c|c|c|c|}
\hline \multirow[b]{2}{*}{ 13. Guilty } & mean & 0.44 & 0.25 & 0.18 & 0.35 & 0.33 \\
\hline & $95 \%-C I$ & $(0.36-0.54)$ & $\begin{array}{l}(0.19- \\
0.33)\end{array}$ & $\begin{array}{l}(0.15- \\
0.21)\end{array}$ & $\begin{array}{l}(0.30- \\
0.40)\end{array}$ & $\begin{array}{c}(0.26- \\
0.40)\end{array}$ \\
\hline \multirow[b]{2}{*}{ 14. Thinking } & mean & 0.41 & 0.24 & 0.19 & 0.39 & 0.40 \\
\hline & $95 \%-C I$ & $(0.32-0.51)$ & $\begin{array}{l}(0.18- \\
0.32)\end{array}$ & $\begin{array}{l}(0.16- \\
0.22)\end{array}$ & $\begin{array}{l}(0.35- \\
0.45)\end{array}$ & $\begin{array}{c}(0.32- \\
0.48)\end{array}$ \\
\hline \multicolumn{7}{|c|}{ Counting/Checking } \\
\hline \multirow[b]{2}{*}{ 15. Count } & mean & 0.33 & 0.06 & 0.07 & 0.12 & 0.21 \\
\hline & $95 \%-C I$ & $(0.25-0.33)$ & $\begin{array}{l}(0.03- \\
0.12)\end{array}$ & $\begin{array}{c}(0.05- \\
0.09)\end{array}$ & $\begin{array}{l}(0.09- \\
0.16)\end{array}$ & $\begin{array}{c}(0.15- \\
0.29)\end{array}$ \\
\hline \multirow[b]{2}{*}{ 16. Check } & mean & 0.28 & 0.13 & 0.06 & 0.11 & 0.18 \\
\hline & $95 \%-C I$ & $(0.21-0.37)$ & $\begin{array}{l}(0.09- \\
0.20)\end{array}$ & $\begin{array}{l}(0.05- \\
0.06)\end{array}$ & $\begin{array}{l}(0.08- \\
0.14)\end{array}$ & $\begin{array}{c}(0.12- \\
0.25)\end{array}$ \\
\hline \multirow{2}{*}{$\begin{array}{l}\text { 17. Do } \\
\text { Certain }\end{array}$} & mean & 0.48 & 0.24 & 0.14 & 0.18 & 0.39 \\
\hline & $95 \%-C I$ & $(0.38-0.57)$ & $\begin{array}{l}(0.18- \\
0.32)\end{array}$ & $\begin{array}{l}(0.11- \\
0.17)\end{array}$ & $\begin{array}{c}(0.14- \\
0.22)\end{array}$ & $\begin{array}{c}(0.31- \\
0.47)\end{array}$ \\
\hline \multicolumn{7}{|l|}{ Hoarding } \\
\hline \multirow{2}{*}{ 18. Throwing } & mean & 0.41 & 0.28 & 0.33 & 0.35 & 0.45 \\
\hline & $95 \%-C I$ & $(0.33-0.50)$ & $\begin{array}{l}(0.22- \\
0.36)\end{array}$ & $\begin{array}{l}(0.30- \\
0.37)\end{array}$ & $\begin{array}{l}(0.31- \\
0.39)\end{array}$ & $\begin{array}{c}(0.38- \\
0.53)\end{array}$ \\
\hline \multirow[b]{2}{*}{ 19. Useless } & mean & 0.39 & 0.25 & 0.28 & 0.30 & 0.41 \\
\hline & $95 \%-C I$ & $(0.31-0.48)$ & $\begin{array}{c}(0.19- \\
0.32)\end{array}$ & $\begin{array}{l}(0.25- \\
0.32)\end{array}$ & $\begin{array}{l}(0.26- \\
0.34)\end{array}$ & $\begin{array}{c}(0.34- \\
0.49)\end{array}$ \\
\hline \multicolumn{7}{|l|}{ Other } \\
\hline \multirow{2}{*}{$\begin{array}{l}20 . \\
\text { Homework }\end{array}$} & mean & 0.13 & 0.08 & 0.04 & 0.08 & 0.07 \\
\hline & $95 \%-C I$ & $(0.08-0.19)$ & $0.13)$ & $\begin{array}{l}\left(0.0 L^{-}\right. \\
0.05)\end{array}$ & $\begin{array}{l}\left(0.06^{-}\right. \\
0.10)\end{array}$ & $\begin{array}{c}(0.04- \\
0.12)\end{array}$ \\
\hline \multirow[b]{2}{*}{ 21. Upsetting } & mean & 0.33 & 0.20 & 0.18 & 0.36 & 0.35 \\
\hline & $95 \%-C I$ & $(0.25-0.43)$ & $\begin{array}{l}(0.14- \\
0.27) \\
\end{array}$ & $\begin{array}{c}(0.15- \\
0.21) \\
\end{array}$ & $\begin{array}{l}(0.32- \\
0.41)\end{array}$ & $\begin{array}{c}(0.28- \\
0.43) \\
\end{array}$ \\
\hline
\end{tabular}


Table S2. Wilcoxon-Signed Rank Test for Parent-Child Agreement on the Toronto Obsessive

Compulsive Scale (TOCS; $\mathbf{n = 3 3 2 ) . ~ T h e ~ m e a n ~ s c o r e s ~ a n d ~ s t a n d a r d ~ d e v i a t i o n s ~ f o r ~ t h e ~ p a r e n t - r e p o r t e d ~ a n d ~}$ self-reported TOCS scores are shown in the table. Most self-reported item scores were higher than the parent-reported scores. The TOCS total score is highlighted in the table and the "interfere" item was omitted from analyses due to incomplete information.

\begin{tabular}{|c|c|c|c|c|c|c|}
\hline TOCS item & $\begin{array}{l}\text { Parent-Reported } \\
\text { Score (Mean, SD) }\end{array}$ & $\begin{array}{c}\text { Self-Reported } \\
\text { Score } \\
\text { (Mean, SD) } \\
\end{array}$ & $\begin{array}{c}\text { Self }<\text { Parent } \\
\text { n } \\
\end{array}$ & f>Parent & $\begin{array}{c}\text { Ties } \\
\mathbf{n} \\
\end{array}$ & p-value \\
\hline Thinking & $-0.72(1.57)$ & $0.45(1.50)$ & 56 & 205 & 71 & $<0.001$ \\
\hline Total & $-21.35(23.12)$ & $-12.77(19.60)$ & 120 & 204 & 8 & $<0.001$ \\
\hline Do certain & $-1.48(1.61)$ & $-0.69(1.72)$ & 81 & 179 & 72 & $<0.001$ \\
\hline Check & $-1.47(1.55)$ & $-0.65(1.66)$ & 75 & 177 & 80 & $<0.001$ \\
\hline Symmetry & $-1.12(1.70)$ & $-0.37(1.85)$ & 77 & 176 & 79 & $<0.001$ \\
\hline Guilty & $-.72(1.63)$ & $0.03(1.69)$ & 86 & 176 & 70 & $<0.001$ \\
\hline Healthy & $-1.19(1.64)$ & $-0.60(1.67)$ & 87 & 173 & 72 & $<0.001$ \\
\hline Count & $-1.64(1.45)$ & $-0.90(1.61)$ & 79 & 165 & 88 & $<0.001$ \\
\hline Repeat & $-1.18(1.56)$ & $-0.69(1.44)$ & 93 & 164 & 75 & $<0.001$ \\
\hline Clean & $-0.76(1.53)$ & $-0.30(1.32)$ & 94 & 151 & 87 & $<0.001$ \\
\hline Special & $-1.87(1.39)$ & $-1.35(1.62)$ & 84 & 151 & 97 & $<0.001$ \\
\hline Useless & $-0.95(1.65)$ & $-0.58(1.79)$ & 110 & 149 & 73 & 0.003 \\
\hline Not exactly & $-0.64(1.68)$ & $-0.25(1.56)$ & 103 & 148 & 81 & $<0.001$ \\
\hline Throwing & $-0.37(1.70)$ & $-0.17(1.83)$ & 111 & 146 & 75 & 0.063 \\
\hline Wash & $-0.70(1.52)$ & $-0.26(1.41)$ & 86 & 138 & 108 & $<0.001$ \\
\hline Upsetting & $-0.94(1.66)$ & $-0.77(1.56)$ & 107 & 136 & 89 & 0.129 \\
\hline Bad luck & $-1.73(1.38)$ & $-1.59(1.46)$ & 105 & 127 & 100 & 0.243 \\
\hline Dirt & $-0.66(1.58)$ & $-0.58(1.63)$ & 124 & 122 & 86 & 0.476 \\
\hline Homework & $-1.06(1.63)$ & $-1.10(1.54)$ & 123 & 121 & 88 & 0.682 \\
\hline Ruined & $-1.27(1.59)$ & $-1.42(1.46)$ & 142 & 111 & 79 & 0.128 \\
\hline Germs & $-0.89(1.60)$ & $-0.98(1.61)$ & 133 & 100 & 99 & 0.335 \\
\hline Interfere & item missing on pap & ersion of the TOCS & & & & \\
\hline
\end{tabular}


Acknowledgements: This work was a part of the primary author's master's thesis project at the University of Toronto. This study is supported by operating grants from the Canadian Institutes of Health Research awarded to Paul Arnold (MOP-106573) and to Russell Schachar (MOP-93696). The authors are grateful to all the families who participated in the study, the Ontario Science Centre for providing the place for data collection, as well as all research team members involved in recruiting participants and collecting data.

Financial Disclosures: Russell Schachar consults for Highland Therapeutics Purdue Pharma and ehave, and is the Toronto Dominion Bank Financial Group Chair in Child and Adolescent Psychiatry. Miss Park, Mrs. Shan, Drs. Burton, Dupuis, Storch, Crosbie and Arnold have no biomedical financial interests or potential conflicts of interest to declare. 